\title{
Impact of Artificial Waste on the Strength of Cementitious Composites ${ }^{\dagger}$
}

\author{
Agnieszka Kocot* and Tomasz Ponikiewski \\ Department of Civil Engineering, Silesian University of Technology, Akademicka 5, 44-100 Gliwice, Poland; \\ tomasz.ponikiewski@polsl.pl \\ * Correspondence: a.koziolek@onet.eu \\ + Presented at the 1st International Conference on Smart Materials for Sustainable Construction-SMASCO \\ 2019, Luleå, Sweden, 10-12 December 2019.
}

Published: 18 November 2019

\begin{abstract}
Every year number of municipal wastes increases. Despite of belonging to the countries with landfill ban, over 35\% of municipal wastes in Poland were disposed to landfills in 2018. Abandoned artificial wastes can endanger whole environment including human. Scientists and students try to reduce arising number of artificial wastes by turning it into construction materials. Plastic waste material can replace natural aggregate in cementitious composites. Addition of artificial wastes decreases density of composites, but also affects their strength significantly. Properties of cementitious composites containing artificial wastes depend on the amount of added plastic material and its type. In the article different types of artificial wastes substituted natural aggregate in mortar. Alternative aggregate were PET flakes, PET pellet, powdered PVC and shredded HDPE. Aggregate was replaced in the amount of $2 \%, 5 \%$ and $10 \%$ of volume of sand. Control sample consisted of Portland cement CEMI 42,5R with water/cement/aggregate ratio 0.5:1:3. Samples were cured in water until the examination and weighed before the test. Compressive and flexural strength tests were conducted after 2 and 28 days. Mortars containing artificial wastes presented similar results to control sample after 2 days of curing. The difference was more significant after 28 days, the compressive strength decreased up to $30 \%$ for mortars containing $10 \%$ of artificial wastes. After flexural strength test mortars containing PET flakes were difficult to divide into two parts. Additionally, the impact resistance of mortar containing 5\% PET flakes was examined. According to the assumption, the results were higher for samples containing PET flakes in comparison to control mortar. The addition of different artificial wastes led to compressive and flexural strength decrease. However, the results of impact resistance test are higher for samples containing PET flakes in comparison to control mortar. The results show that addition of artificial wastes could improve some properties of mortar; still further tests need to be conducted in order to qualify artificial wastes as valuable component of cementitious composite.
\end{abstract}

Keywords: cementitious composite; artificial waste; plastic waste aggregate; PET; HDPE; compressive strength

(C) 2019 by the authors. Licensee MDPI, Basel, Switzerland. This article is an open access article distributed under the terms and conditions of the Creative Commons Attribution (CC BY) license (http://creativecommons.org/licenses/by/4.0/). 